\title{
An active component containing pterodontic acid and pterodondiol isolated from Laggera pterodonta inhibits influenza A virus infection through the TLR7/MyD88/TRAF6/NF-кB signaling pathway
}

\author{
YUTAO WANG $^{1 *}$, JING LI $^{1 *}$, WEN YAN ${ }^{2 *}$, QIAOLIAN CHEN ${ }^{1}$, ZHIHONG JIANG ${ }^{1,3}$, \\ RONGPING ZHANG ${ }^{4}$, XIPING PAN ${ }^{5}$ and XINHUA WANG ${ }^{1}$
}

\begin{abstract}
${ }^{1}$ State Key Laboratory of Respiratory Disease, National Clinical Research Center for Respiratory Disease,
First Affiliated Hospital of Guangzhou Medical University, Guangzhou, Guangdong 510120; ${ }^{2}$ Institute of Tropical Medicine, Guangzhou University of Chinese Medicine, Guangzhou, Guangdong 510405; ${ }^{3}$ State Key Laboratory of Quality Research in Chinese Medicine, Macau Institute for Applied Research in Medicine and Health, Macau University of Science and Technology, Taipa, Macau SAR 999078; ${ }^{4}$ School of Pharmaceutical Science and Biomedical Engineering Research Center, Yunnan Key Laboratory of Pharmacology for Natural Products, Kunming Medical University, Kunming, Yunnan 650500;

${ }^{5}$ Institute of Chinese Integrative Medicine, Guangzhou Medical University, Guangzhou, Guangdong 511436, P.R. China
\end{abstract}

Received September 27, 2017; Accepted March 13, 2018

DOI: $10.3892 / \mathrm{mmr} .2018 .8947$

\begin{abstract}
The influenza virus is a pathogen that can cause pandemic and epidemic outbreaks, and therefore represents a severe threat to human health. Antiviral drugs have an important role in the prevention and treatment of influenza, although the increasing emergence of drug resistance has given rise to a requirement for the development of novel antiviral drugs. In the present study, an active component (C8) isolated from Laggera pterodonta was evaluated. The nuclear magnetic resonance spectroscopy and mass spectrometry analysis results revealed that two eudesmane-type sesquiterpene compounds were identified in C8; pterodontic acid and pterodondiol. C8 was demonstrated to have a broad-spectrum effect against different influenza viruses, including human and avian influenza viruses, with a half maximal inhibitory concentration value of $19.9-91.4 \mu \mathrm{g} / \mathrm{ml}$. The antiviral mechanisms of C8 were further clarified. Western blot analysis verified that C8 inhibited Toll-like receptor 7, myeloid differentiation primary response protein 88 and tumor necrosis factor (TNF) receptor associated factor 6 expression, in addition to p65
\end{abstract}

Correspondence to: Professor Xinhua Wang, State Key Laboratory of Respiratory Disease, National Clinical Research Center for Respiratory Disease, First Affiliated Hospital of Guangzhou Medical University, 151 Yanjiang Road, Guangzhou, Guangdong 510120, P.R. China

E-mail: xinhuaw@gzhmu.edu.cn

${ }^{*}$ Contributed equally

Key words: Laggera pterodonta, influenza virus, nuclear factor- $\mathrm{kB}$ signaling pathway, anti-inflammatory phosphorylation, at a concentration of 100 or $150 \mu \mathrm{g} / \mathrm{ml}$. An indirect immunofluorescence assay demonstrated that $\mathrm{C} 8$ may inhibit p65/NF- $\mathrm{kB}$ nuclear translocation. Additionally, C8 prevented an increase in cytokine mRNA expression, including interleukin (IL)-1 $\beta$, IL-6, IL-8 and C-C motif chemokine 2 (MCP-1). Furthermore, the Bio-Plex assay results indicated that the protein expression of IL-6, IL-8, TNF- $\alpha, \mathrm{C}-\mathrm{X}-\mathrm{C}$ motif chemokine 10, MCP-1 and C-C motif chemokine 5 was inhibited. These findings suggest that $\mathrm{C} 8$ has the potential to be developed into an anti-inflammatory drug for the prevention and treatment of influenza A virus infection.

\section{Introduction}

Influenza viruses are pathogens that cause respiratory infection, in addition to severe viral pneumonia and even mortality (1). A number of pandemic and epidemic outbreaks of influenza have occurred and it represents a severe threat to human health worldwide.

Influenza viruses are negative single-stranded, segmented RNA viruses. There are three types of influenza virus; A, B and C. Influenza A viruses are classified into different subtypes based on hemagglutinin and neuraminidase antigenicity. Due to genetic recombination, new influenza A subtypes continually emerge, including H7N9 and H5N6, which have no suitable vaccines $(2,3)$.

Antiviral drugs have an important role in the prevention and treatment of influenza. At present, adamantine derivatives, including amantadine and rimantadine, in addition to the neuraminidase inhibitors oseltamivir, zanamivir and paramivir, are widely used and effective in the treatment of clinical influenza virus infection (4). However, novel antiviral drugs against resistant strains in particular are required, due to the development of drug resistance (3). 
Traditional Chinese medicine (TCM) is widely used in China to treat respiratory disease. TCM is considered to be safe, effective and multi-targeted (5). Numerous medicinal plants exhibit antiviral activity through different mechanisms and these may lead to the development of novel antiviral drugs (5). Laggera pterodonta is a medicinal plant used widely in China that is primarily distributed in the Yunnan province. Certain antiviral compounds have been isolated from L. pterodonta, including flavonoids, which have an anti-inflammatory and anti-apoptotic effect, in addition to three dicaffeoylquinic acids that display antiviral activity against herpes simplex virus-1, herpes simplex virus-2 and influenza A in vitro (6-8).

The results from a previous study indicated that a sesquiterpene fraction isolated from L. pterodonta demonstrated anti-influenza activity by targeting the nuclear factor- $\kappa \mathrm{B}$ (NF- $\mathrm{KB}$ ) and p38/mitogen-activated protein kinase (MAPK) signaling pathways (9). The present study investigated the C8 fraction, an antiviral component containing pterodontic acid and pterodondiol isolated from L. pterodonta. The mechanisms of action of this antiviral component against influenza A were subsequently investigated in vitro.

\section{Materials and methods}

Plant material, cells and viruses. L. pterodonta $(10 \mathrm{~kg})$ was collected manually during October 2015 in Yunnan (China) and subsequently stored in a dry, ventilated environment. The herbarium specimen was authenticated by Professor Rongping Zhang (Kunming Medical University, Kunming, China) and deposited in the College of Pharmaceutical Sciences (Kunming Medical University).

Madin-Darby canine kidney (MDCK) and A549 cells were purchased from the American Type Culture Collection (ATCC; Manassas, VA, USA). The cells were grown in Dulbecco's modified Eagle's medium (Gibco; Thermo Fisher Scientific, Inc., Waltham, MA, USA) with $10 \%$ heat-inactivated fetal calf serum (Gibco; Thermo Fisher Scientific, Inc.). A/PR/8/34 was purchased from ATCC. A/Guangzhou/GIRD/07/09 (H1N1), A/Guangzhou/GIRD/02/09 (H1N1) and influenza $B$ virus were isolated from routine clinical throat swab specimens of infected patients treated in the First Affiliated Hospital of Guangzhou Medical University (Guangzhou, China). Several strains of avian influenza virus, including A/Duck/Guangdong/2009 (H6N2), A/Duck/Guangdong/1994 (H7N3) and A/Chicken/Guangdong/1996 (H9N2); were provided by Dr Jianxin Chen (South China Agricultural University, Guangzhou, China) and subsequently stored in State Key Laboratory of Respiratory Disease, Guangzhou Medical University. The influenza viruses were grown in the allantoic cavity of embryonated chicken eggs for $48 \mathrm{~h}$ at $35^{\circ} \mathrm{C}$, followed by $12 \mathrm{~h}$ at $4^{\circ} \mathrm{C}(9)$. Following this, the harvested viruses were preserved at $80^{\circ} \mathrm{C}$ prior to further experimentation.

General experimental procedures. Ultra-high-performance liquid chromatography/quadrupole-time of flight-mass spectrometry (UHPLC/Q-TOF-MS) was performed using Agilent 1290 UHPLC (Agilent Technologies, Inc., Santa Clara, CA, USA) and Bruker maXis impact Q-TOF-MS (Bruker Corporation, Billerica, MA, USA) systems. Column chromatography (CC) was performed using silica gel (200-300 mesh;
Qingdao Haiyang Chemical Co., Ltd., Qingdao, China), Thin layer chromatography was performed on pre-coated silica gel $\mathrm{GF}_{254}$ plates. Spots were visualized under UV light (254 or $356 \mathrm{~nm}$ ) or using iodine fuming. All solvents used were of analytical grade and were purchased from Guangzhou Chemical Reagents Factory. HPLC grade acetonitrile was purchased from Merck KGaA (Darmstadt, Germany). HPLC grade methanol was purchased from RCI Labscan, Ltd. (Bangkok, Thailand). HPLC grade formic acid was purchased from Merck KGaA (Darmstadt, Germany).

Preparation of standards. Pterodontic acid and pterodondiol were isolated from L. pterodonta in the laboratory, and were identified by MS and nuclear magnetic resonance spectroscopy analysis (purity, $>98 \%$ ). Pterodontic acid $(1.25 \mathrm{mg}$ ) and pterodondiol (0.99 mg) were accurately weighed and dissolved in $1 \mathrm{ml}$ methanol to give individual stock solutions. Pterodontic acid stock solution was subsequently diluted to $6.25 \mu \mathrm{g} / \mathrm{ml}$ and pterodondiol stock solution $4.95 \mu \mathrm{g} / \mathrm{ml}$. All solutions were stored at $4^{\circ} \mathrm{C}$ prior to UHPLC-Q-TOF-MS analysis.

Preparation of the C8 fraction. Powdered plant material $(1 \mathrm{~kg})$ was extracted with methanol by percolation, followed by the collection and vacuum concentration of 401 eluate to yield $135 \mathrm{~g}$ methanol extract. The extract was suspended in $\mathrm{H}_{2} \mathrm{O}(800 \mathrm{ml})$ and subjected to liquid-liquid partition by the addition of petroleum ether. The residue ( $48 \mathrm{~g}$ ) of the petroleum ether layer was subjected to silica gel CC (petroleum ether-ethyl acetate, 10:1) to obtain the C8 fraction (38 g) (10).

Sample preparation. C8 (0.01 g) was accurately weighed into a 5-ml volumetric flask and dissolved in methanol, and additional methanol was subsequently added to give a final volume of $5 \mathrm{ml}$. The sample solution was filtered through a $0.22-\mu \mathrm{m}$ polytetrafluoroethylene filter and diluted 20 times for UHPLC/Q-TOF-MS analysis.

UHPLC/Q-TOF-MS system. UHPLC was performed with the Agilent 1290 ultra-high performance liquid chromatography system (Agilent Technologies, Inc.). The chromatography was performed on an Agilent Poroshell 120 EC-C18 column (150x3.0 mm, $2.7 \mu \mathrm{m}$; Agilent Technologies, Inc.). The mobile phase consisted of solvent $\mathrm{A}$ (water with $0.1 \%$ formic acid) and solvent B (acetonitrile with $0.1 \%$ formic acid). The following gradient elution procedure was used: $0-8 \mathrm{~min}, 30-70 \% \mathrm{~B}$; 8-13 min, $70-100 \% \mathrm{~B} ; 13-16 \mathrm{~min}, 100 \% \mathrm{~B}$. The flow rate was $0.35 \mathrm{ml} / \mathrm{min}$, the injection volume was $2 \mu \mathrm{l}$, and the column temperature was maintained at $30^{\circ} \mathrm{C}$. Eluted compounds were detected with an Agilent diode array detector (Agilent Technologies, Inc.) over a wavelength range of 200-400 nm.

Mass spectrometry was performed on a Q-TOF-MS with an electrospray ionization interface (Bruker Corporation) operating in the positive mode. The Q-TOF-MS source parameters were as follows: End plate offset, $-500 \mathrm{~V}$; capillary voltage, 4,000 V; collision energy, $7 \mathrm{eV}$; nebulizing gas $\left(\mathrm{N}_{2}\right)$ pressure, 2.0 bar; drying gas $\left(\mathrm{N}_{2}\right)$ flow rate, $8.0 \mathrm{l} / \mathrm{min}$; drying gas temperature, $200^{\circ} \mathrm{C}$; and mass range, $\mathrm{m} / \mathrm{z}$ 100-1,300.

Cytotoxicity assay (MTT assay). The 50\% toxic concentration $\left(\mathrm{TC}_{50}\right)$ of $\mathrm{C} 8$ was determined. MDCK cells $\left(2 \times 10^{4}\right.$ cells/well $)$ 
were seeded into 96 -well plate for $24 \mathrm{~h}$ at $37^{\circ} \mathrm{C}$ and subsequently washed with PBS. The cells were treated with the indicated amounts of C8 $(0,12.5,25,50,100$ and $200 \mu \mathrm{g} / \mathrm{ml})$ and cultured at $37^{\circ} \mathrm{C}$ for $48 \mathrm{~h}$. The cytotoxicity of the $\mathrm{C} 8$ was measured with an MTT assay, as previously described (10). The $\mathrm{TC}_{50}$ was calculated using the Reed-Muench method (11).

Cytopathic effect (CPE) inhibition assay. MDCK cells $\left(1.0 \times 10^{4}\right.$ cells/well) were seeded in 96 -well plates and grown to $90 \%$ confluence at $37^{\circ} \mathrm{C}$ for $24 \mathrm{~h}$. To clearly observe the anti-influenza activity of $\mathrm{C} 8, \mathrm{MDCK}$ cells were washed with PBS and infected with 100 median tissue culture infective dose $\left(\mathrm{TCID}_{50}\right)$ of $\mathrm{A} / \mathrm{PR} / 8 / 34(\mathrm{H} 1 \mathrm{~N} 1)$ at $37^{\circ} \mathrm{C}$ for $2 \mathrm{~h}$. Following medium removal, different concentrations of $\mathrm{C} 8$ (two-fold dilution) in serum-free Minimum Essential Medium (MEM; Gibco; Thermo Fisher Scientific, Inc., Waltham, MA, USA) supplemented with $2 \mu \mathrm{g} / \mathrm{ml}$ tosyl phenylalanyl chloromethyl ketone-trypsin. Following incubation for $48 \mathrm{~h}$ at $37^{\circ} \mathrm{C}$, the cytopathogenic efficiency (CPE) of the influenza virus was measured microscopically using a MI12 inverted phase contrast microscope (Micro-shot Technology Limited, Guangzhou, China; magnification, x200). The concentration required for $50 \%$ inhibition of the virus-induced $\mathrm{CPE}$ (half-maximal inhibitory concentration; $\mathrm{IC}_{50}$ ) was calculated by the Reed-Muench method (11). The selection index was calculated by the ratio of $\mathrm{TC}_{50} / \mathrm{IC}_{50}(12)$.

Western blot analysis. A549 cells $\left(2 \times 10^{4}\right.$ cells/well) were cultured at $37^{\circ} \mathrm{C}$ under $5 \% \mathrm{CO}_{2}$ for $24 \mathrm{~h}$. Following this, cells were washed with PBS and subsequently incubated with $\mathrm{A} / \mathrm{PR} / 8 / 34$ virus [multiplicity of infection $(\mathrm{MOI})=0.1$ ], diluted in PBS, for $30 \mathrm{~min}$ at $37^{\circ} \mathrm{C}$. Following this, the inoculums were discarded and cells were incubated with MEM in the absence and presence of different concentrations (100 and $150 \mu \mathrm{g} / \mathrm{ml}$ ) of $\mathrm{C} 8$ for $24 \mathrm{~h}$ at $37^{\circ} \mathrm{C}$. Cell lysis and western blot analysis was performed as previously described (13). Cells were lysed on ice for $10 \mathrm{~min}$ with radioimmunoprecipitation assay lysis buffer (Beyotime Institute of Biotechnology, Haimen, China) supplemented with a phosphatase inhibitor cocktail (Beyotime Institute of Biotechnology). Protein concentration was determined with the bicinchoninic protein assay kit. Proteins (30 ng/lane) were separated using $10 \%$ SDS-PAGE and subsequently electrotransferred onto polyvinylidene fluoride (PVDF) membranes. The PVDF membrane was blocked with $5 \%$ bovine serum albumin (BSA; 9048-46-8; GBCBIO Technologies Inc., Guangzhou, China)/TBS-Tween 20 for $1 \mathrm{~h}$ at room temperature prior to incubation at $4^{\circ} \mathrm{C}$ overnight with antibodies against Toll-like receptor 7 (TLR7; cat. no. 2633), myeloid differentiation primary response protein 88 (MyD88; cat. no. 4283), tumor necrosis factor (TNF) receptor associated factor 6 (TRAF6; cat. no. 8028), phosphorylated-p65 (cat. no. 3033), p65 (cat. no. 8242) and GAPDH (cat. no. 2118); all at a dilution of 1:1,000 and purchased from CST Biological Reagents Co., Ltd. (Shanghai, China). Following this, membranes were incubated with a horseradish peroxidase-conjugated secondary antibody (cat. no. 7074; 1:5,000; CST Biological Reagents Co., Ltd.) for $60 \mathrm{~min}$ at room temperature. The complexes were detected using a western lighting chemiluminescence system (Thermo Fisher Scientific, Inc.).
Table I. Primers and probes used in the reverse transcriptionquantitative polymerase chain reaction analysis.

\begin{tabular}{lll}
\hline Gene & \multicolumn{1}{c}{ Type } & \multicolumn{1}{c}{ Sequence $\left(5^{\prime} \rightarrow 3^{\prime}\right)$} \\
\hline IL-1 $\beta$ & $\begin{array}{l}\text { Forward } \\
\text { Reverse }\end{array}$ & GCACGATGCACCTGTACGAT \\
& Probe & ACTGAACTGCACGCTCCGGGA \\
& & CTC \\
IL-6 & Forward & CGGGAACGAAAGAGAAGCTCTA \\
& Reverse & CGCTTGTGGAGAAGGAGTTCA \\
& Probe & TCCCCTCCAGGAGCCCAGCT \\
IL-8 & Forward & TTGGCAGCCTTCCTGATTTC \\
& Reverse & TATGCACTGACATCTAAGTTCTT \\
& & TAGCA \\
& Probe & CCTTGGCAAAACTGCACCTTCAC \\
& & ACA \\
MCP-1 & Forward & CAAGCAGAAGTGGGTTCAGGAT \\
& Reverse & AGTGAGTGTTCAAGTCTTCGGA \\
& & GTT \\
& Probe & CATGGACCACCTGGACAAGCAA \\
& & ACC \\
GAPDH & Forward & GAAGGTGAAGGTCGGAGTC \\
& Reverse & GAAGATGGTGATGGGATTTC \\
& Probe & CAAGCTTCCCGTTCTCAGCC \\
& &
\end{tabular}

IL, interleukin; MCP-1, C-C motif chemokine ligand 2.

Indirect immunofluorescence assay. A549 cells were seeded into 48 -well plates at $37^{\circ} \mathrm{C}$ with $5 \% \mathrm{CO}_{2}$. When the cell culture reached 50-70\% confluence, cell were incubated with $/ \mathrm{PR} / 8 / 34$ $(\mathrm{H} 1 \mathrm{~N} 1 ; \mathrm{MOI}=5)$ virus or TNF- $\alpha(20 \mathrm{ng} / \mathrm{ml} ; 300-01 \mathrm{~A}$; PeproTech China, Suzhou, China) for $2 \mathrm{~h}$ at $37^{\circ} \mathrm{C}$. The supernatant was subsequently aspirated, cells were washed twice with PBS and C8 $(75,100$ and $150 \mu \mathrm{g} / \mathrm{ml})$ was added to wells. After $9 \mathrm{~h}$, cells were washed three times with PBS and fixed with $4 \%$ paraformaldehyde in PBS for $15 \mathrm{~min}$ at $4^{\circ} \mathrm{C}$. Cells were permeabilized with $0.5 \%$ Triton X-100 in PBS for 15 min at room temperature and blocked with $3 \%$ BSA in PBS for $30 \mathrm{~min}$ at $37^{\circ} \mathrm{C}$, followed by incubation with anti-p65 antibody (1:50; cat. no. 8242; CST Biological Reagents Co., Ltd.) overnight at $4^{\circ} \mathrm{C}$. Following a further wash, cells were incubated with fluorescein isothiocyanate-conjugated secondary antibody (1:100; cat. no. SA00003; ProteinTech Group, Inc., Chicago, IL, USA) at $37^{\circ} \mathrm{C}$ for $1 \mathrm{~h}$. The nuclei were stained with DAPI (5 $\mu \mathrm{g} / \mathrm{ml}$; cat. no. 10236276001; Sigma-Aldrich; Merck $\mathrm{KGaA}$, Darmstadt, Germany) for $30 \mathrm{sec}$ at room temperature, and fluorescence was visualized using a Zeiss Axiovert 135 fluorescence microscope (Zeiss AG, Oberkochen, Germany; magnification, $\mathrm{x}$ 400) (14).

Reverse transcription-quantitative polymerase chain reaction (RT-qPCR) assay. A549 cells were cultured in 96-well plates at $37^{\circ} \mathrm{C}$ with $5 \% \mathrm{CO}_{2}$ for $24 \mathrm{~h}$, and subsequently infected with $\mathrm{A} / \mathrm{PR} / 8 / 34$ virus $(\mathrm{MOI}=0.1)$ for $2 \mathrm{~h}$ at $37^{\circ} \mathrm{C}$. The inoculums were discarded and the cells were treated with various concentrations of $\mathrm{C} 8(100$ and $200 \mu \mathrm{g} / \mathrm{ml})$ for $24 \mathrm{~h}$ at $37^{\circ} \mathrm{C}$. 
Table II. Content of the two sesquiterpenes in C8.

\begin{tabular}{lccc}
\hline Sample & $\begin{array}{c}\text { Retention } \\
\text { time, min }\end{array}$ & $\begin{array}{c}\text { Content, } \\
\mathrm{mg} / \mathrm{g}\end{array}$ & RSD, \% \\
\hline Pterodondiol & 7.58 & 111.3 & 1.3 \\
Pterodontic acid & 12.59 & 107.98 & 4.7 \\
\hline
\end{tabular}

RSD, relative standard deviation.

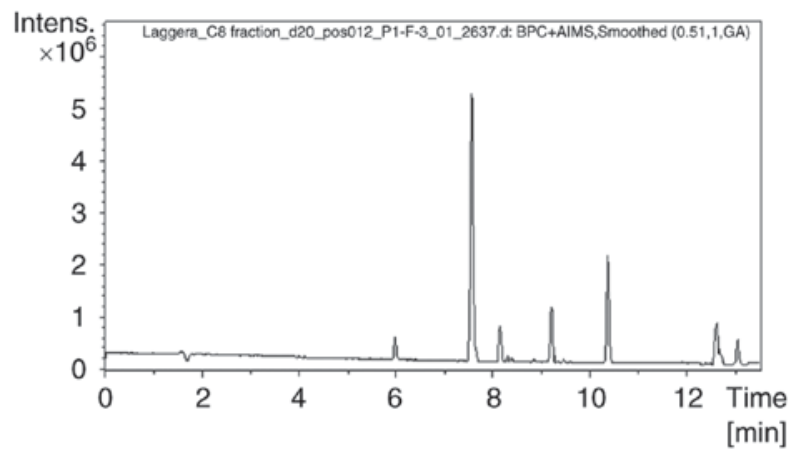

Figure 1. Base peak chromatograms of C8. Intens, intensity.

Total RNA was extracted using TRIzol reagent (Invitrogen; Thermo Fisher Scientific, Inc.). Total RNA (1 $\mu \mathrm{g})$ was reverse transcribed into cDNA using the Prime-Script RT-PCR kit (Takara Biotechnology Co., Ltd., Dalian, China) at $50^{\circ} \mathrm{C}$ for 30 min. qPCR was performed using an ABI7500 Real-time PCR System (Applied Biosystems; Thermo Fisher Scientific, Inc.) with the following thermocycling conditions: $95^{\circ} \mathrm{C}$ for $30 \mathrm{sec}$, followed by 35 cycles of $95^{\circ} \mathrm{C}$ for $5 \mathrm{sec}$ and $60^{\circ} \mathrm{C}$ for $40 \mathrm{sec}$ (15). Relative gene expression levels of C-C motif chemokine ligand 2 (MCP-1), interleukin (IL)-1 $\beta$, IL-6, IL-8 and GAPDH were calculated using the $2^{-\triangle \Delta C q}$ method (16). The RT-qPCR primers and probes for analyses are listed in Table I.

Bio-Plex assay. A549 cells $\left(1 \times 10^{5}\right.$ cells/well $)$ were grown in 6-well plates at $37^{\circ} \mathrm{C}$ with $5 \% \mathrm{CO}_{2}$ for $24 \mathrm{~h}$ and subsequently washed with $\mathrm{PBS}$ twice. $\mathrm{A} / \mathrm{PR} / 8 / 34$ virus $(\mathrm{MOI}=0.1)$ was incubated with the cells for $2 \mathrm{~h}$, followed by treatment with various concentrations of $\mathrm{C} 8(100$ and $150 \mu \mathrm{g} / \mathrm{ml})$ at $37^{\circ} \mathrm{C}$ for $24 \mathrm{~h}$. The supernatants were collected after $24 \mathrm{~h}$ treatment and centrifuged at $16,000 \mathrm{x} \mathrm{g}$ at $4^{\circ} \mathrm{C}$ to remove cell debris. IL-6, IL-8, TNF- $\alpha$, C-X-C motif chemokine 10 (IP-10), MCP-1 and C-C motif chemokine 5 (RANTES) were detected using the Bio-Plex liquid phase chips kit (Bio-Rad Laboratories, Inc., Hercules, CA, USA) with the Bio-Plex 200 system (Bio-Rad Laboratories, Inc.) (17).

Statistical analysis. Statistical analyses were performed using SPSS 18.0 (SPSS, Inc., Chicago, IL, USA). One-way analysis of variance followed by Fisher's Least Significant Difference post-hoc test was used to calculate statistical significance. Data are presented as the mean \pm standard deviation. Experiments were performed in triplicate. $\mathrm{P}<0.05$ was considered to indicate a statistically significant difference.
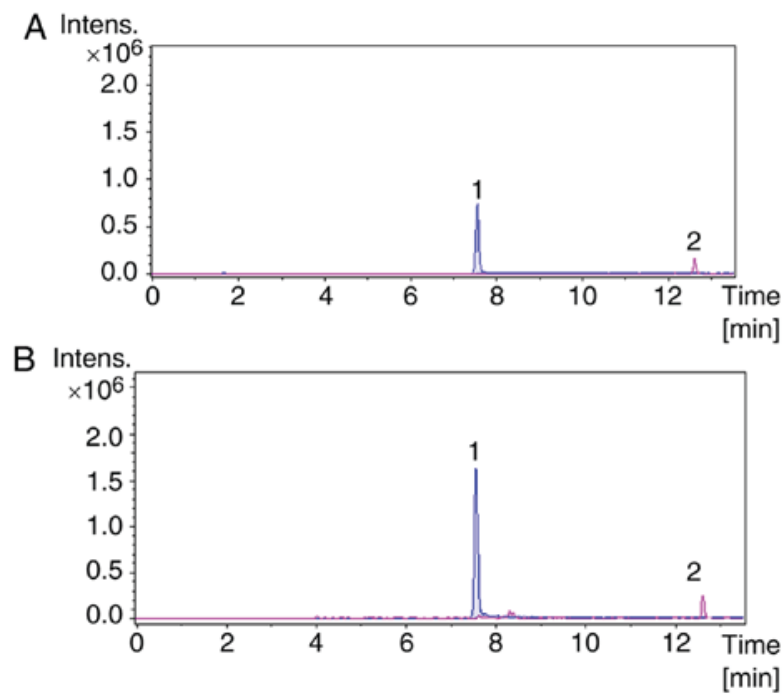

Figure 2. Extraction ion chromatograms. Extraction ion chromatograms of (A) the standards and (B) C8. Peak 1 indicates pterodondiol and peak 2 indicates pterodontic acid. Intens, intensity.

\section{Results}

Quantification of sesquiterpenes in C8. The presence of pterodontic acid and pterodondiol in $\mathrm{C} 8$ was determined by UHPLC/Q-TOF-MS in the positive ion mode. Base peak chromatograms of sample $\mathrm{C} 8$ are presented in Fig. 1. Extraction ion chromatograms of the two standards and C8 are presented in Fig. 2. The results (Table II) obtained from UHPLC-Q-TOF-MS analysis determined that the pterodontic acid and pterodondiol content in C8 was 107.98 and $111.3 \mathrm{mg} / \mathrm{g}$, respectively. These results provided essential data required for the identification and quality control of $\mathrm{C} 8$ obtained from L. pterodonta.

Cytotoxicity and anti-influenza activity of C8. C8 was examined for its cytotoxic ability in confluent MDCK cell cultures. No significant cytotoxic effects were observed at $>200 \mu \mathrm{g} / \mathrm{ml}$. To evaluate the anti-influenza activity of $\mathrm{C} 8$, MDCK cells were infected with influenza virus $\left(100 \mathrm{TCID}_{50}\right)$ and $\mathrm{C} 8$ was added at increasing concentrations. Following treatment for $48 \mathrm{~h}$, the antiviral effect of C8 was evaluated. C8 exhibited an antiviral effect on a number of influenza virus strains, with $\mathrm{IC}_{50}$ values of 19.9-91.4 $\mu \mathrm{g} / \mathrm{ml}$ (Table III).

Inhibition of the TLR7/MyD88/TRAF6/NF- $\kappa B$ signaling pathway. TLR7 recognizes influenza single-stranded RNA and subsequently combines with the adapter protein MyD88, which induces the phosphorylation of IL-1 receptor-associated kinase 1 (IRAK) through IRAK4. Following this, IRAK1 interacts with TRAF6, which is able to activate the NF- $\kappa B$ signaling pathway $(18,19)$. Western blot analysis indicated that C8 inhibited TLR7, MyD88, TRAF6 and p-p65 phosphorylation levels at 100 and $150 \mu \mathrm{g} / \mathrm{ml}$ (Fig. 3).

Inhibition of $p 65 / N F-\kappa B$ nuclear translocation. p65-p50 constitutes the typical NF- $\kappa B$ inhibitor (I $\mathrm{BB}$ ) proteins, the p50 and p65 complex translocates to the nucleus to promote the inflammatory response $(20,21)$. The results revealed that $\mathrm{C} 8$ 
Table III. Anti-influenza spectrum of C8.

\begin{tabular}{lccc}
\hline Strain & $\mathrm{TC}_{50}, \mu \mathrm{g} / \mathrm{ml}$ & $\mathrm{IC}_{50}, \mu \mathrm{g} / \mathrm{ml}$ & $\mathrm{SI}$ \\
\hline A/PR/8/34, H1N1 & $>200$ & 25 & $>8$ \\
A/Guangzhou/GIRD/07/09, H1N1 & $>200$ & 50 & $>4$ \\
A/Guangzhou/GIRD/02/09, H1N1 & $>200$ & 19.9 & $>10.1$ \\
Influenza B & $>200$ & 50 & $>4$ \\
A/Duck/Guangdong/2009, H6N2 & $>200$ & 84.8 & $>2.36$ \\
A/Duck/Guangdong/1994, H7N3 & $>200$ & 80.2 & $>2.49$ \\
A/Chicken/Guangdong/1996, H9N2 & $>200$ & 91.4 & $>2.19$
\end{tabular}

$\mathrm{TC}_{50}, 50 \%$ toxic concentration; $\mathrm{IC}_{50}$, half maximal inhibitory concentration; SI, Selection index $\left(\mathrm{SI}=\mathrm{TC}_{50} / \mathrm{IC}_{50}\right)$.

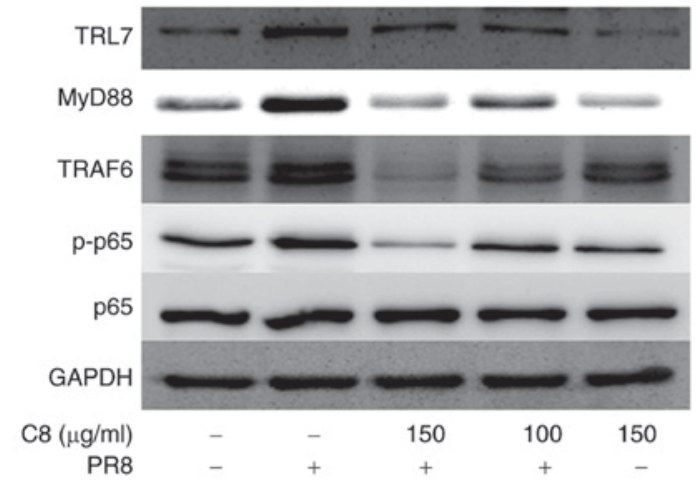

Figure 3. Inhibitory effects of C8 against the TLR7/MyD88/TRAF6/NF-кB signaling pathway, determined by western blot analysis. A549 cells were incubated with $\mathrm{A} / \mathrm{PR} / 8 / 34$ virus $(\mathrm{MOI}=0.1)$ followed by incubation with or without C8 (100 and $150 \mu \mathrm{g} / \mathrm{ml})$. TLR7, Toll-like receptor 7; MyD88, myeloid differentiation primary response protein 88; TRAF6, tumor necrosis factor receptor associated factor 6 ; NF- $\kappa \mathrm{B}$, nuclear factor- $\kappa \mathrm{B}$; PR8, A/PR/8/34, p-p65, phosphorylated p65.

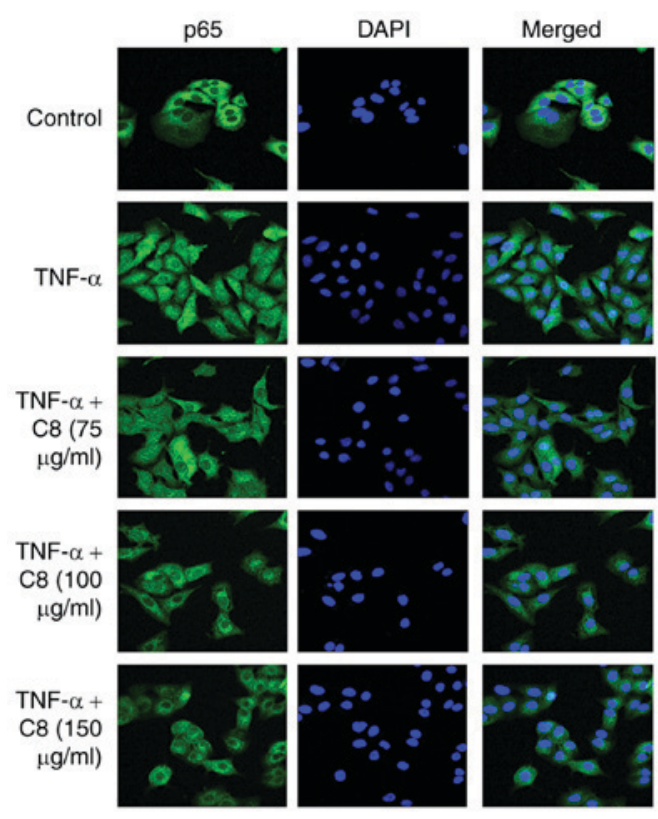

Figure 4. p65/NF- $\mathrm{B}$ nuclear translocation induced by TNF- $\alpha$ is inhibited by C 8 . TNF- $\alpha(20 \mathrm{ng} / \mathrm{ml})$ was added to A549 cells, followed by incubation with C8 $(75,100$ and $150 \mu \mathrm{g} / \mathrm{ml})$. Cells were stained with anti-p65 antibody and the nuclei were stained with DAPI. Magnification, $\mathrm{x} 400$. NF- $\mathrm{BB}$, nuclear factor- $\kappa \mathrm{B}$; TNF- $\alpha$, tumor necrosis factor $\alpha$; PR8, A/PR/8/34.

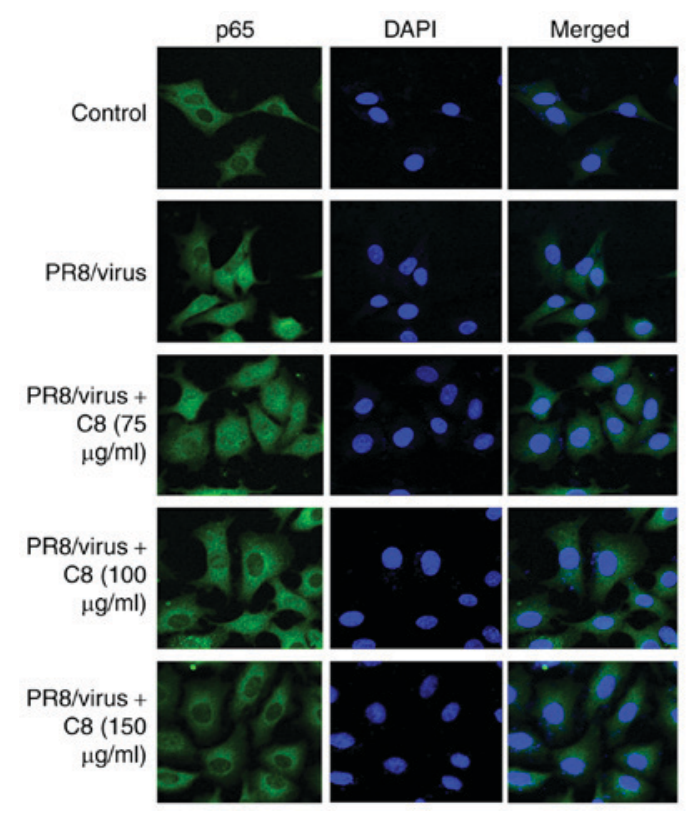

Figure 5. p65/nuclear factor- $\kappa \mathrm{B}$ nuclear translocation induced by influenza virus is inhibited by $\mathrm{C} 8$. The virus $\mathrm{A} / \mathrm{PR} / 8 / 34(\mathrm{H} 1 \mathrm{~N} 1$; $\mathrm{MOI}=5)$ was incubated with A549 cells followed by the addition of C8 $(75,100$ and $150 \mu \mathrm{g} / \mathrm{ml})$. Cells were stained with anti-p65 antibody and the nuclei were stained with DAPI. Magnification, $x 400$. PR8, A/PR/8/34.

inhibited p65 nuclear translocation induced by TNF- $\alpha$ (Fig. 4) and influenza virus (Fig. 5).

Inhibition of the mRNA and protein expression of inflammatory cytokines. The effects of $\mathrm{C} 8$ on inducing cytokine production were determined. The results revealed that the IL-1 $\beta$, IL-6, IL-8 and MCP-1 mRNA expression was significantly reduced in $\mathrm{C} 8$-treated cells after $24 \mathrm{~h}(\mathrm{P}<0.05$; Fig 6). The results of the Bio-Plex assay demonstrated that the protein expression of IL-6, IL-8, TNF- $\alpha$, IP-10, MCP-1 and RANTES was inhibited $(\mathrm{P}<0.001$; Fig. 7).

\section{Discussion}

Influenza viruses have the ability to cause severe pandemic or epidemic outbreaks, particularly through the transmission of avian influenza viruses to humans, which may lead to the development of novel virus strains capable of causing a pandemic 

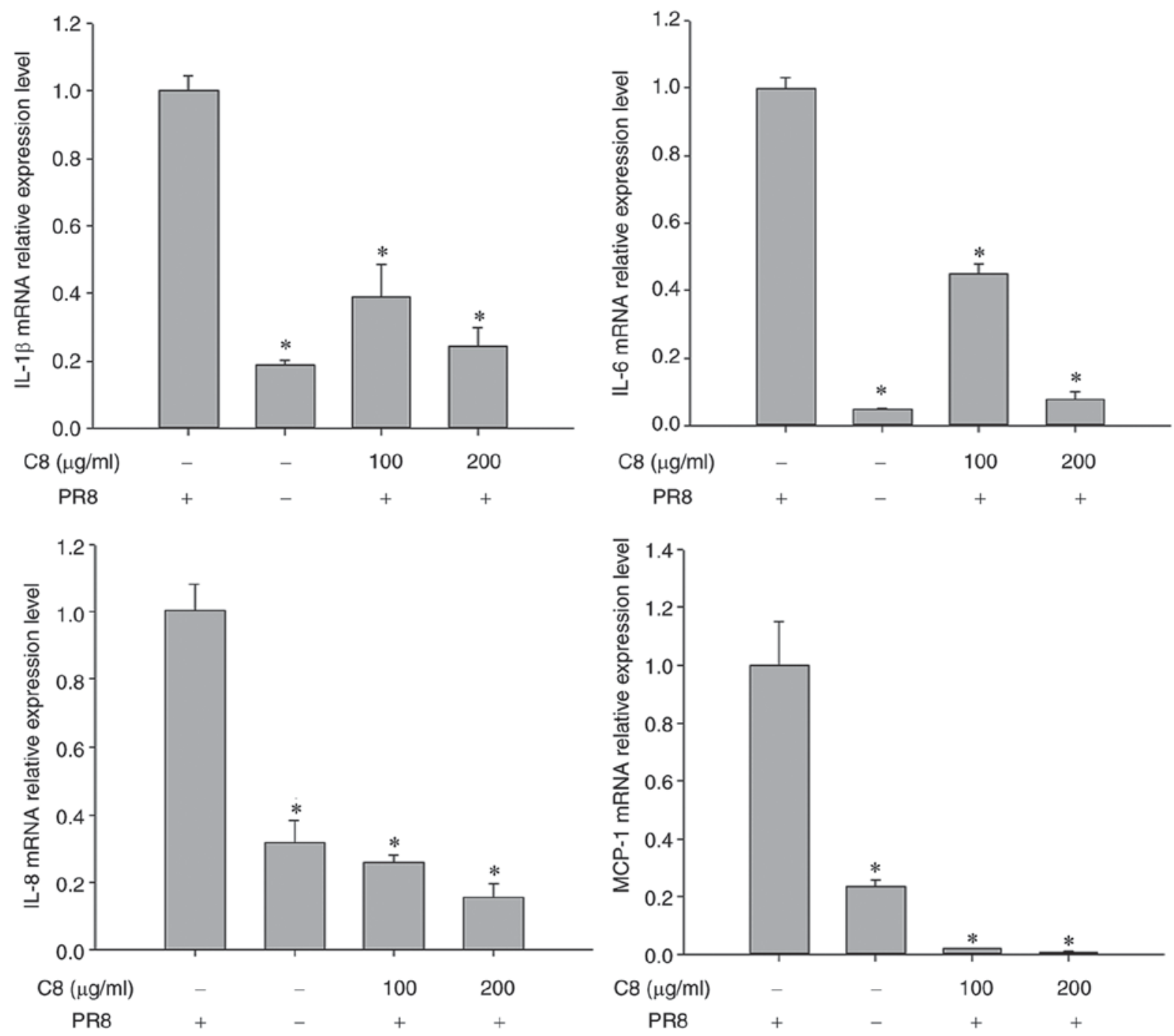

Figure 6. Inhibition of inflammatory cytokine mRNA expression by C8 in A549 cells following influenza virus infection. A549 cells were infected with influenza virus and subsequently treated with C8 (100 and $200 \mu \mathrm{g} / \mathrm{ml})$. The expression of IL-1 $\beta$, IL-6, IL-8 and MCP-1 was determined by reverse transcription-quantitative polymerase chain reaction. The data are presented as the mean \pm standard deviation of three independent experiments. ${ }^{*} \mathrm{P}<0.05$ vs. virus control. IL, interleukin; MCP-1, C-C motif chemokine ligand 2.

outbreak. The majority of currently available antiviral drugs target the viral proteins of influenza. However, the clinical use of these drugs is limited due to increasing drug resistance, and alternative antiviral targets are required. Influenza viruses take advantage of host cellular functions to support efficient viral replication. Numerous studies have reported that cell signaling pathways are involved in the influenza virus life cycle, such as NF-kB (21), Raf/mitogen-activated protein kinase/extracellular signal-regulated kinase (22), phosphatidylinositol 3-kinase/protein kinase B (23) and p38/MAPK (24) pathways. The results of a genome-wide RNA interference screen in mammalian cells revealed that 219 of the 295 factors were identified to be required for efficient wild-type influenza virus replication. Therefore, the development of drugs that are able inhibit host factors essential for influenza virus replication may be an alternative and more effective therapeutic strategy $(25,26)$.

In the present study, the antiviral component $\mathrm{C} 8$ was isolated from the traditional Chinese medicine L. pterodonta and its activity against influenza virus was evaluated. The results revealed that $\mathrm{C} 8$ was effective against different influenza virus stains, including human and avian, with $\mathrm{IC}_{50}$ values of 19.9-91.4 $\mu \mathrm{g} / \mathrm{ml}$. The anti-inflammatory activity of C8 was subsequently examined.

The host innate inflammatory response is mediated by pattern recognition receptors (PRRs). The TLR family is an important class of PRRs that recognizes pathogen-associated molecular patterns. There are ten TLRs in humans: TLR2, TLR4, TLR5, TLR6 and TLR11 are located at the cell surface; TLR3, TLR7, TLR9 and TLR13 are intracellular receptors. Additionally, TLR7 is able to recognize single-stranded RNA $(18,19)$.

The influenza virus infects the host cell and releases its RNA, which is recognized by TLR7. MyD88 is a TLR7 adapter protein, which induces the phosphorylation of IRAK1 via IRAK4. IRAK1 subsequently interacts with TRAF6, which is able to activate NF- $\mathrm{KB}(19)$.

Activation of the NF- $\mathrm{kB}$ signaling pathway is required for efficient influenza virus replication. In mammals, it contains

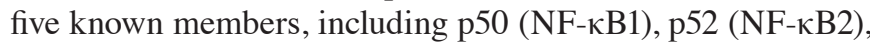
p65 (RelA or NF- $\kappa$ B3), RelB, and c-Rel. The NF- $\kappa$ B signaling pathway has a central role in host immune response regulation, cell adhesion, differentiation and apoptosis (20). A previous 

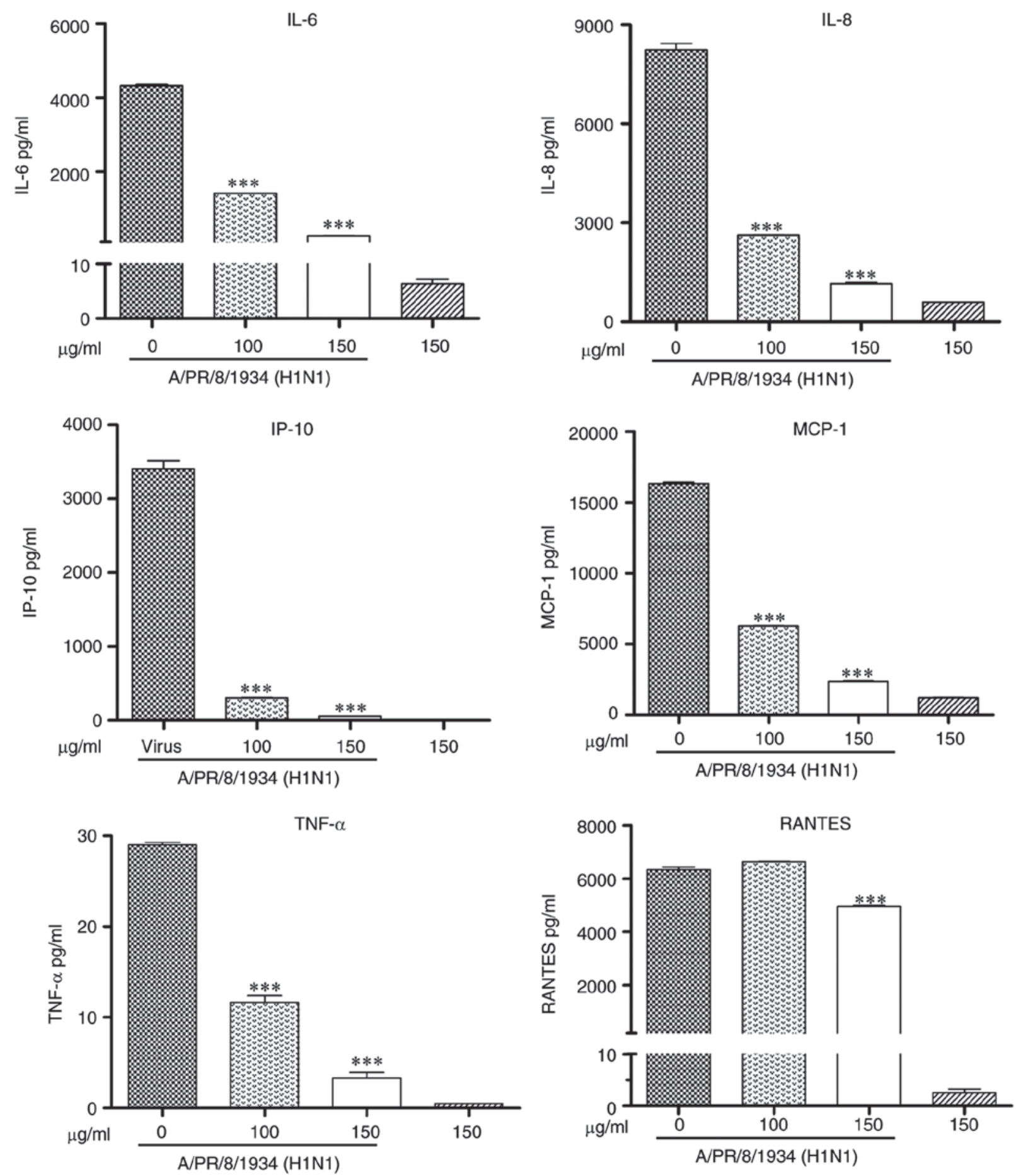

Figure 7. Inhibition of inflammatory cytokine protein expression by C8 in A549 cells following influenza virus infection. A549 cells were infected with influenza virus and subsequently treated with C8 (100 and $150 \mu \mathrm{g} / \mathrm{ml})$. Protein expression of IL-6, IL-8, TNF- $\alpha$, IP-10, MCP-1 and RANTES was detected using the Bio-Plex liquid phase chips kit with the Bio-Plex 200 system. The data are presented as the mean \pm standard deviation of three independent experiments. ${ }^{* * *} \mathrm{P}<0.001$ vs. virus control. IL, interleukin; TNF- $\alpha$, tumor necrosis factor $\alpha$; IP-10, C-X-C motif chemokine ligand 10; MCP-1, C-C motif chemokine ligand 2; RANTES, C-C motif chemokine ligand 5.

study reported that active NF- $\mathrm{KB}$ signaling is a prerequisite for influenza virus infection (21).

The results of the western blot analysis in the present study demonstrated that C8 inhibited TLR7/MyD88/TRAF6 expression and p65 phosphorylation. Additionally, the western blot analysis results demonstrated that C8 may inhibit the nuclear translocation of p65 at different concentrations (100 and $150 \mu \mathrm{g} / \mathrm{ml}$ ). p65 is an important member of the NF- $\kappa B$ pathway; following proteasomal degradation of cytosolic I $\kappa \mathrm{B}$ proteins, the p50 and p65 complex translocates into the nucleus to promote the inflammatory response. These results suggested that C8 may inhibit the NF- $\mathrm{KB}$ signaling pathway through two different mechanisms.

Following viral infection, cell death may activate the immune response, and the production of cytokines and chemokines, including TNF- $\alpha$, MCP-1, RANTES, IP-10 and 
IL-8 (27). IL-6 is a pro-inflammatory cytokine that is able to activate T cells. Previous studies have demonstrated that IL-6 may be a potential disease severity biomarker for severe pandemic H1N1 influenza A infection $(27,28)$. Additionally, $\mathrm{NF}-\kappa \mathrm{B}$ is involved in producing an effective immune and inflammatory response against viral infections and induces the transcription of pro-inflammatory cytokines, including TNF- $\alpha$, IL- 6 and IL- 8 (21). The results of the present study demonstrated that the expression of IL-1 $\beta$, IL- 6 , IL- 8 and MCP-1 mRNA was decreased following treatment with C8. Furthermore, the Bio-Plex results revealed that protein levels of IL-6, IL-8, TNF- $\alpha$, IP-10, MCP-1 and RANTES had decreased.

$\mathrm{NF}-\kappa \mathrm{B}$ inhibition may result in substantial clinical benefit and it is a potential target for the development of novel anti-influenza virus therapies. However, inhibition may additionally lead to detrimental effects on health (29) and its detailed mechanism requires investigation in future research.

Although the present study demonstrated the potential immunoregulatory mechanisms of $\mathrm{C} 8, \mathrm{C} 8$ is a component containing a number of monomer compounds. Thus, further study is required to verify the exact targets and mechanisms of each monomer compound isolated from C8.

\section{Acknowledgements}

Not applicable.

\section{Funding}

The present study was supported by the National Natural Science Foundation of China (grant nos. U1502226 and 81460593), the Engineering Technology Research Center of Guangdong General Universities (grant no. GCZX-A1408), Key Projects of Applied Basic Research in Yunnan Province (grant no. 2014FA031), Guangzhou Municipal Science and Technology Program-Technology Benefiting Special (grant no. 2014Y2-00031), Collaborative Innovation Major Projects of Guangzhou Health Care (grant no. 201400000002), and the Science Research Project of the Guangdong Province (grant no. 2016A050503047).

\section{Availability of data and materials}

The datasets used and/or analyzed during the current study are available from the corresponding author on reasonable request.

\section{Authors' contributions}

YW performed data collection and analysis, and was involved in the drafting of the manuscript. JL, XP and RZ participated in fraction isolation and characterization analysis. YW, WY and QC participated in the virological experimentation. ZJ and XW designed the study and were involved in the revising of the manuscript. All of the authors read and approved the final manuscript.

\section{Ethics approval and consent to participate}

Not applicable.

\section{Consent for publications}

Not applicable.

\section{Competing interests}

The authors declare that they have no competing interests.

\section{References}

1. Marois I, Cloutier A, Meunier I, Weingartl HM, Cantin AM and Richter MV: Inhibition of influenza virus replication by targeting broad host cell pathways. PLoS One 9: e110631, 2014.

2. Saladino R, Barontini M, Crucianelli M, Nencioni L, Sgarbanti R and Palamara AT: Current advances in anti-influenza therapy. Curr Med Chem 17: 2101-2140, 2010.

3. Hussain M, Galvin HD, Haw TY, Nutsford AN and Husain M: Drug resistance in influenza a virus: The epidemiology and management. Infect Drug Resist 10: 121-134, 2017.

4. De Clercq E: Antiviral agents active against influenza A viruses. Nat Rev Drug Discov 5: 1015-1025, 2006.

5. Wang X, Jia W, Zhao A and Wang X: Anti-influenza agents from plants and traditional Chinese medicine. Phytother Res 20: 335-341, 2006.

6. Wu Y, Zhou C, Li X, Song L, Wu X, Lin W, Chen H, Bai H, Zhao J, Zhang R, et al: Evaluation of antiinflammatory activity of the total flavonoids of Laggera pterodonta on acute and chronic inflammation models. Phytother Res 20: 585-590, 2006.

7. Cao C, Liu B, Zeng C, Lu Y, Chen S, Yang L, Li B, Li Y and Li Y: A polymethoxyflavone from Laggera pterodonta induces apoptosis in imatinib-resistant K562R cells via activation of the intrinsic apoptosis pathway. Cancer Cell Int 14: 137, 2014.

8. Shi S, Huang K, Zhang Y, Zhao Y and Du Q: Purification and identification of antiviral components from Laggera pterodonta by high-speed counter-current chromatography. J Chromatogr B Analyt Technol Biomed Life Sci 859: 119-124, 2007.

9. Wang Y, Zhou B, Lu J, Chen Q, Ti H, Huang W, Li J, Yang Z, Jiang $Z$ and Wang $X$ : Inhibition of influenza virus via a sesquiterpene fraction isolated from Laggera pterodonta by targeting the NF- $\mathrm{kB}$ and p38 pathways. BMC Complement Altern Med 17: $25,2017$.

10. Li J,Zhou B, Li C, Chen Q, Wang Y, Li Z, Chen T, Yang C, Jiang Z, Zhong $\mathrm{N}$, et al: Lariciresinol-4-O- $\beta$-D-glucopyranoside from the root of Isatis indigotica inhibitsinfluenza A virus-induced pro-inflammatory response. J Ethnopharmacol 174: 379-386, 2015.

11. Reed LJ and Muench H: A simple method of estimating fifty percent endpoints. Am J Hyg 27: 493-497, 1938.

12. Zu M, Yang F, Zhou W, Liu A, Du G and Zheng L: In vitro anti-influenza virus and anti-inflammatory activities of theaflavin derivatives. Antiviral Res 94: 217-224, 2012.

13. Wu W, Li R, Li X, He J, Jiang S, Liu S and Yang J: Quercetin as an antiviral agent inhibits influenza a virus (IAV) entry. Viruses 8: E6, 2016.

14. Uetani K, Hiroi M, Meguro T, Ogawa H, Kamisako T, Ohmori Y and Erzurum SC: Influenza A virus abrogates IFN-gamma response in respiratory epithelial cells bydisruption of the Jak/Stat pathway. Eur J Immunol 38: 1559-1573, 2008.

15. Ding Y, Zeng L, Li R, Chen Q, Zhou B, Chen Q, Cheng PL, Yutao W, Zheng J, Yang Z and Zhang F: The Chinese prescription lianhuaqingwen capsule exerts anti-influenza activitythrough the inhibition of viral propagation and impacts immune function. BMC Complement Altern Med 17: 130, 2017.

16. Livak KJ and Schmittgen TD: Analysis of relative gene expression data using real-time quantitative PCR and the 2(-Delta Delta C(T)) method. Methods 25: 402-408, 2001.

17. Mok CK, Kang SS, Chan RW, Yue PY, Mak NK, Poon LL, Wong RN, Peiris JS and Chan MC: Anti-inflammatory and antiviral effects of indirubin derivatives ininfluenza A (H5N1) virus infected primary human peripheral blood-derived macrophages and alveolar epithelial cells. Antiviral Res 106: 95-104, 2014.

18. Ramirez-Ortiz ZG, Prasad A, Griffith JW, Pendergraft WF III, Cowley GS, Root DE, Tai M, Luster AD, El Khoury J, Hacohen N and Means TK: The receptor TREML4 amplifies TLR7-mediated signaling during antiviral responses and autoimmunity. Nat Immunol 16: 495-504, 2015. 
19. O'Neill LA, Golenbock D and Bowie AG: The history of Toll-like receptors-redefining innate immunity. Nat Rev Immunol 13: 453-460, 2013.

20. Vitiello M, Galdiero M, Finamore E, Galdiero S and Galdiero M: $\mathrm{NF}-\mathrm{\kappa B}$ as a potential therapeutic target in microbial diseases. Mol Biosyst 8: 1108-1120, 2012.

21. Nimmerjahn F, Dudziak D, Dirmeier U, Hobom G, Riedel A Schlee M, Staudt LM, Rosenwald A, Behrends U, Bornkamm GW and Mautner J: Active NF-kappaB signalling is a prerequisite for influenza virus infection. J Gen Virol 85: 2347-2356, 2004.

22. Pleschka S, Wolff T, Ehrhardt C, Hobom G, Planz O, Rapp UR and Ludwig S: Influenza virus propagation is impaired by inhibition of the Raf/MEK/ERK signaling cascade. Nat Cell Biol 3: 301-305, 2001

23. Wu MS, Yen HR, Chang CW, Peng TY, Hsieh CF, Chen CJ, Lin TY and Horng JT: Mechanism of action of the suppression of influenza virus replication by Ko-Ken Tang through inhibition of the phosphatidylinositol 3-kinase/Akt signaling pathway and viral RNP nuclear export. J Ethnopharmacol 134: 614-623, 2011.
24. Holzberg M, Boergeling Y, Schräder T, Ludwig S and Ehrhardt C: Vemurafenib limits influenza a virus propagation by targeting multiple signaling pathways. Front Microbiol 8: 2426, 2017.

25. König R, Stertz S, Zhou Y, Inoue A, Hoffmann HH, Bhattacharyya S, Alamares JG, Tscherne DM, Ortigoza MB, Liang Y, et al: Human host factors required for influenza virus replication. Nature 463: 813-817, 2010.

26. Watanabe T, Watanabe $S$ and Kawaoka Y: Cellular networks involved in the influenza virus life cycle. Cell Host Microbe 7: 427-439, 2010.

27. La Gruta NL, Kedzierska K, Stambas J and Doherty PC: A question of self-preservation: Immunopathology in influenza virus infection. Immunol Cell Biol 85: 85-92, 2007.

28. Paquette SG, Banner D, Zhao Z, Fang Y, Huang SS, León AJ, $\mathrm{Ng}$ DC, Almansa R, Martin-Loeches I, Ramirez P, et al: Interleukin-6 is a potential piomarker for severe pandemic $\mathrm{H} 1 \mathrm{~N} 1$ Influenza A infection. PLoS One 7: e38214, 2012.

29. Planz O: Development of cellular signaling pathway inhibitors as new antiviral against influenza. Antiviral Res 98: 457-468, 2013. 